\title{
A NEW DATA ACQUISITION SYSTEM FOR THE GRONINGEN COUNTERS
}

\author{
JOHANNES VAN DER PLICHT, H. J. STREURMAN and G. R. SCHREUDER ${ }^{1}$
}

Center for Isotope Research, University of Groningen, Nijenborgh 4 9747 AG Groningen, The Netherlands

\begin{abstract}
A new GPIB/IEEE-488 based data acquisition system has been built for the Groningen proportional counter setup, consisting of 11 counters. The IEEE bus is connected to an XT-compatible host PC. A versatile computer program controls the data entry; the same program can be used offline for final calculations.
\end{abstract}

\section{INTRODUCTION}

The Groningen laboratory operates 11 proportional counters; 3 are used for tritium and 8 for radiocarbon. Three of the ${ }^{14} \mathrm{C}$ counters can be combined into one large high-precision counter. Table 1 summarizes the main properties of the Groningen counters. The counters are numbered $1-9 ; 3,4$ and 5 are the tritium counters, and 9 consists of the subsets A, B and C. The counter system developed for milligram-sized samples (Counter 10; Hut, Keyser \& Wijma 1983) is not included; this setup was contaminated because of the Chernobyl accident, and is decommissioned.

Each counter system has its own amplifier (within the lead shielding close to the proportional counter) and discriminator unit. Until 1990, the discriminator units were read out by an ITT 2020 (Apple IIe compatible) microcomputer via a locally designed interface. Secondary parameters, such as counter gas pressures, temperatures and barometer reading were routed to the same microcomputer via a different locally designed interface. For the large counter (no. 9), not all parameters could be handled by the ITT2020 because of its limited memory $(48 \mathrm{~kb})$.

In 1990, we replaced the ITT2020 with an Olivetti M240 (XT-compatible) PC with an IEEE-based interface system. The discriminator units had to be rebuilt to incorporate the new standard. We also replaced the amplifiers with modern ones with better signal-to-noise ratios and completely rewrote the software for the new data acquisition system into Turbo Pascal.

\section{THE COUNTERS}

We use $\mathrm{CO}_{2}$ as counting gas in the Groningen proportional counters for ${ }^{14} \mathrm{C}$. As is well known, this requires a high degree of gas purity (Mook \& Streurman 1983; Brenninkmeijer \& Mook 1979). In routine $\mathrm{CO}_{2}$ counter operation, the gas purity is determined in the counter itself. At fixed counting conditions (such as high voltage and pressure), electronegative impurities result in a decrease in pulse height; this causes a shift of the beta plateau toward higher voltages. A similar shift occurs in the meson characteristic curve, which is measurable by the decrease in counting rate at the steep part of the curve. The decrease in meson counting rate can be converted to that in the beta counting rate through a comparison of the respective slopes. The corrected count rate then becomes

$$
A_{c}=A_{m}\left[1-\left(N_{z}-N_{z_{0}}\right)\left(\frac{d V}{d N_{\mu}}\right)_{\max }\left(\frac{d N_{\beta}}{d V}\right)_{\text {recent }} A_{o}^{-1}\right]
$$

${ }^{1}$ Electronics Department, University of Groningen 
TABLE 1. The Groningen Proportional Counters

\begin{tabular}{lclcccccc}
\hline Counter & $\begin{array}{c}\text { No. of } \\
\text { counters }\end{array}$ & Material & $\begin{array}{c}\text { Volume } \\
(\mathrm{ml})\end{array}$ & $\begin{array}{c}\text { Pressure } \\
(\mathrm{mbar})\end{array}$ & $\begin{array}{c}\text { Min. amt. } \\
\text { of C }(\mathrm{g})\end{array}$ & $\begin{array}{c}\text { Max. age } \\
(\mathrm{BP})^{*}\end{array}$ & $\begin{array}{c}\mathrm{A}_{\mathrm{o}} \\
(\mathrm{cpm})\end{array}$ & $\begin{array}{c}\mathrm{B} \\
(\mathrm{cpm})\end{array}$ \\
\hline 1 & 1 & Quartz & 750 & 2856 & 1.5 & 48,700 & 13.59 & 1.15 \\
2 & 1 & Quartz & 1710 & 2756 & 3.0 & 51,500 & 31.64 & 2.3 \\
$3^{* *+}$ & 1 & Quartz & & & & & & \\
4 & 1 & Quartz & 1663 & 2800 & & & & 1.1 \\
$5^{\dagger}$ & 1 & Copper & 1517 & 3100 & & & & 0.8 \\
6 & 1 & Quartz & 1690 & 2800 & 1.0 & 48,000 & 31.15 & 2.8 \\
7 & 1 & Quartz & 532 & 2667 & 1.0 & 47,100 & 9.675 & 1.1 \\
8 & 1 & Copper & 288 & 3067 & 0.75 & 46,000 & 6.017 & 0.8 \\
9 & 7 & Quartz & 6840 & 2907 & 12.5 & 58,000 & 119.1 & 9.1 \\
(Total) & & & & & & & & \\
$9 \mathrm{~A}$ & 1 & Quartz & 977 & 2907 & 1.9 & 47,000 & 17.5 & 1.7 \\
9B & 3 & Quartz & 2931 & 2907 & 5.3 & 52,000 & 50.2 & 3.6 \\
$9 \mathrm{C}$ & 3 & Quartz & 2931 & 2907 & 5.3 & 52,000 & 51.4 & 3.8 \\
\hline
\end{tabular}

*48-h measuring time; ** Under construction; ${ }^{\dagger}$ Tritium counter

where $A_{c}$ is the purity-corrected count rate in cpm, $A_{m}$ the measured $\beta$-counting rate, and $A_{o}$ the $\beta$-counting rate for standard recent ${ }^{14} \mathrm{CO}_{2}$. The correction terms contain the steep slope of the meson counting rate, and the $\beta$ plateau slope for standard recent ${ }^{14} \mathrm{CO}_{2}$, as Figure 1 shows.

We make a similar correction for background (fossil anthracite) $\mathrm{CO}_{2}$

$$
B_{c}=B_{m}\left[1-\left(N_{z}-N_{z_{0}}\right)\left(\frac{d V}{d N_{\mu}}\right)_{\max }\left(\frac{d N_{B}}{d V}\right)-\left(b-b_{o}\right) \frac{d N_{B}}{d b}\right]
$$

The final calculated activity is then determined by

$$
A_{\text {final }}=\left[A_{c}-B_{c}\right] \frac{T}{T_{0}} \frac{p_{o}}{p} F
$$

where $\mathrm{b}, \mathrm{p}$ and $\mathrm{T}$ stand for barometer, pressure and temperature; $\mathrm{F}$ is the dilution factor used for small samples. For more details (also concerning counter construction), we refer to Grootes (1977) and Tans and Mook (1978).

The relations above obviously apply only to the radiocarbon proportional counters. Counters 4 and 5 are used for tritium with $\mathrm{C}_{2} \mathrm{H}_{6}$ as counting gas (Groeneveld 1977). Counter 3 is under construction and will use propane as counting gas.

\section{ELECTRONICS}

Figure 2 shows a schematic overview of the total counter setup. Each counter has a chargesensitive preamplifier in the lead castle (close to the counter), connected to a controller unit. Also, the anticoincidence Geiger-Müller counters are connected to the controller unit. The preamplifier (model SP $2123 \mathrm{~S}$ ) is a charge-integrating amplifier; the output voltage is proportional to the input charge and does not depend on the counter capacity. The controller unit (model SP226) is a 19-in rack containing an amplifier/discriminator model for the GM counter, an (anti-)coincidence module, a display unit and control buttons. With three adjustable discriminators (indicated as low, medium 


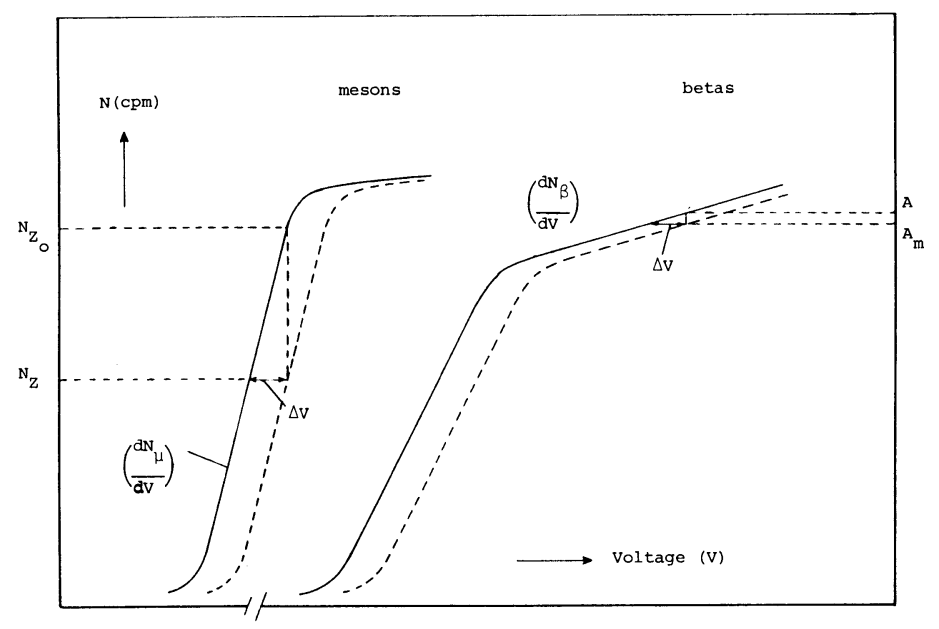

Fig. 1. Correction of $\beta$ counting rate for impurities in $\mathrm{CO}_{2}$

and high), ${ }^{14} \mathrm{C}$ counter pulse is selected as an alpha (or high-energy beta), meson or purity count. The signals are routed to seven electronic counters ("channels"), which can be displayed (on the controller unit itself) and/or read by the host computer.

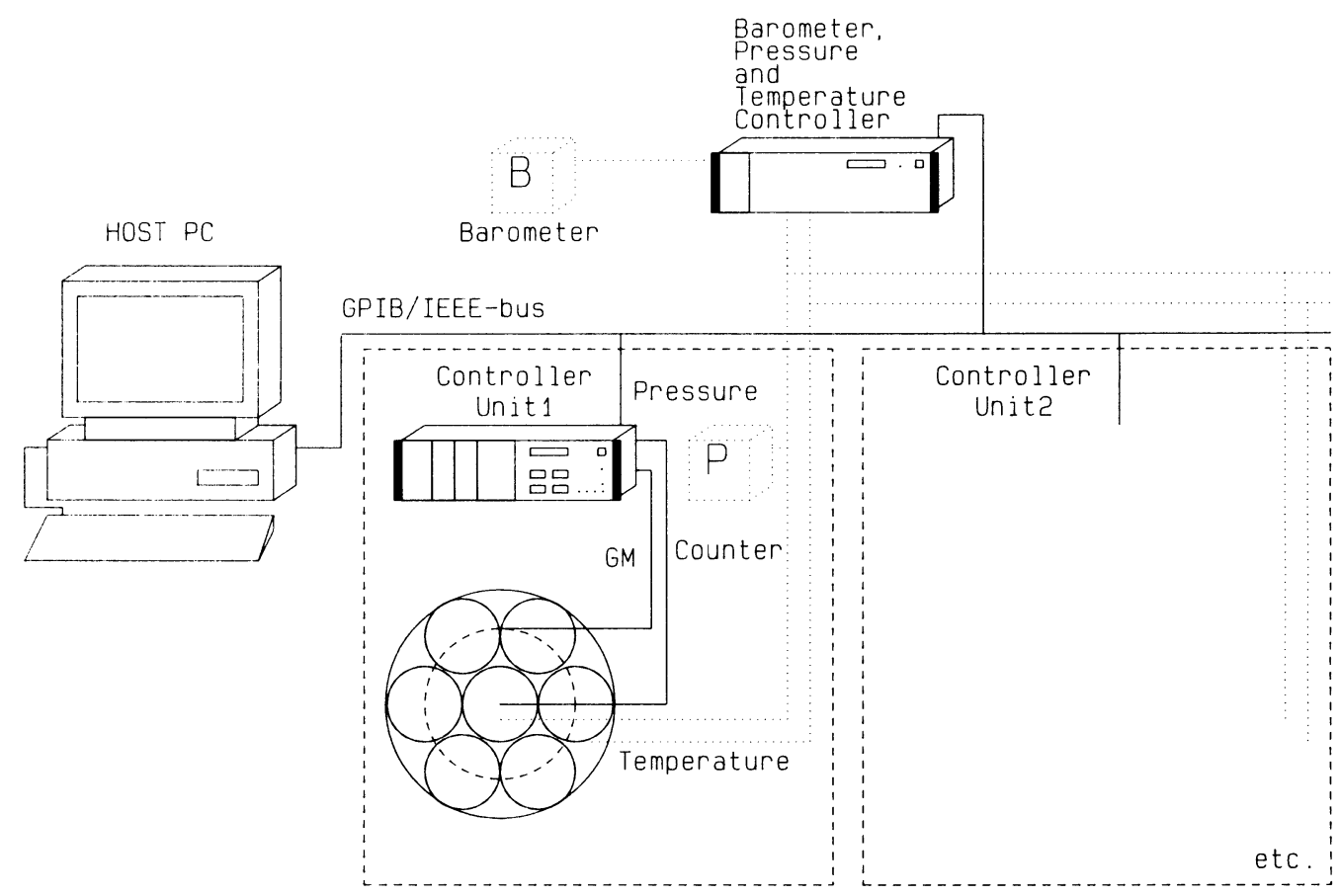

Fig. 2. Schematic overview of the Groningen counter setup

As shown in Figure 2, the system consists of eight identical controller units for Counters 1-8; Counter 9 has a special version, because this counter can be used either as a total large-size counter or as three separate counters that each has its own discriminator/coincidence modules. Each controller unit is connected to a GPIB/IEEE 488 bus through an interface card. The bus is led to the host PC (Olivetti M240, XT compatible) equipped with an IEEE interface card. A separate 
controller collects the external parameters: barometer reading, and - for each counter system pressure and temperature readings. This controller is also connected to the GPIB/IEEE bus. The controller units contain a G-64-based microprocessor (6809), which transfers the units basically into listen/talk state machines. G-64 is one of the standard buses for microprocessor-based systems. Devices (e.g., 133, 134, . , 137; see below) are defined for communication with the display module, timer module, counter (channel) module, ADCs, etc. A special program is present in the 6809 processor; the main control program, TELBUIS (running on the host PC), communicates with the controller units via these devices.

\section{SOFTWARE}

The counter setup is controlled by the program TELBUIS, which is written in Turbo Pascal (version 5) (Borland 1989). The program controls data entry by means of the IEEE bus connection to the counter controller units; it is also used for offline analysis. Figure 3 shows the main menu. The main choices can be activated with function keys F1-F6. Measurements can be started with $\mathrm{F} 1$ or F2. For real measurements, F1 is used; the program is then linked to the counter electronics via IEEE. F2 can be used for testing purposes, and also on computers without an IEEE interface card; in this case, random counts are generated. For daily routine analysis, F3 is used. Measurement cycles (typically $100 \mathrm{~min}$ ) can be excluded, proxy data, such as barometer reading and temperature, are averaged and a report is generated. Definitive results (such as averaging runs, age calculations, etc.) are usually generated offline with F4.

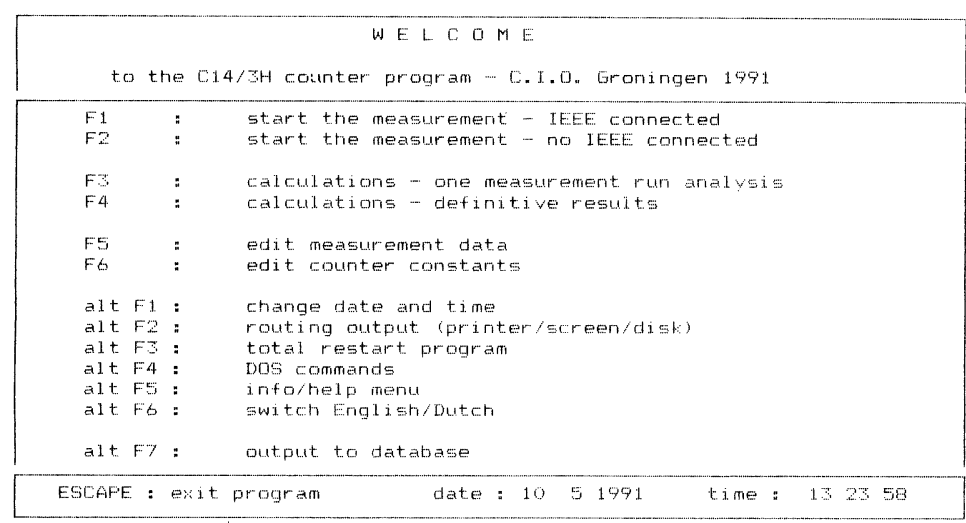

Fig. 3. Main menu for the data acquisition/analysis program, TELBUIS

F5 and F6 are editing functions for measurement data (such as sample name, submitter, etc.) and counter constants, respectively. The keys, alt F1-alt F6 are useful options which can be accessed from the main menu. Alt F7 is reserved for output to other programs, such as the new data base (van der Plicht 1992), and will be installed in the new Groningen Radiocarbon Laboratory.

The program can further be explained using a (simplified) flow diagram (Fig. 4). After the measurement is started (F1, F2 from the main menu), the program asks which counters are connected. For these counters, two files are then called up, one containing the measurement data, and the other containing the counter constants. These files can be edited at this stage. The measurement data file contains administrative data such as $\mathrm{GrN}$-number (for tritium: GT-number), sample number, sample name, submitter, etc. The counter constants data file contains background, recent activity, purity, correction factors, etc.

Next, the program's main loop, a continuous cycle, reading out the connected counters, is entered. 


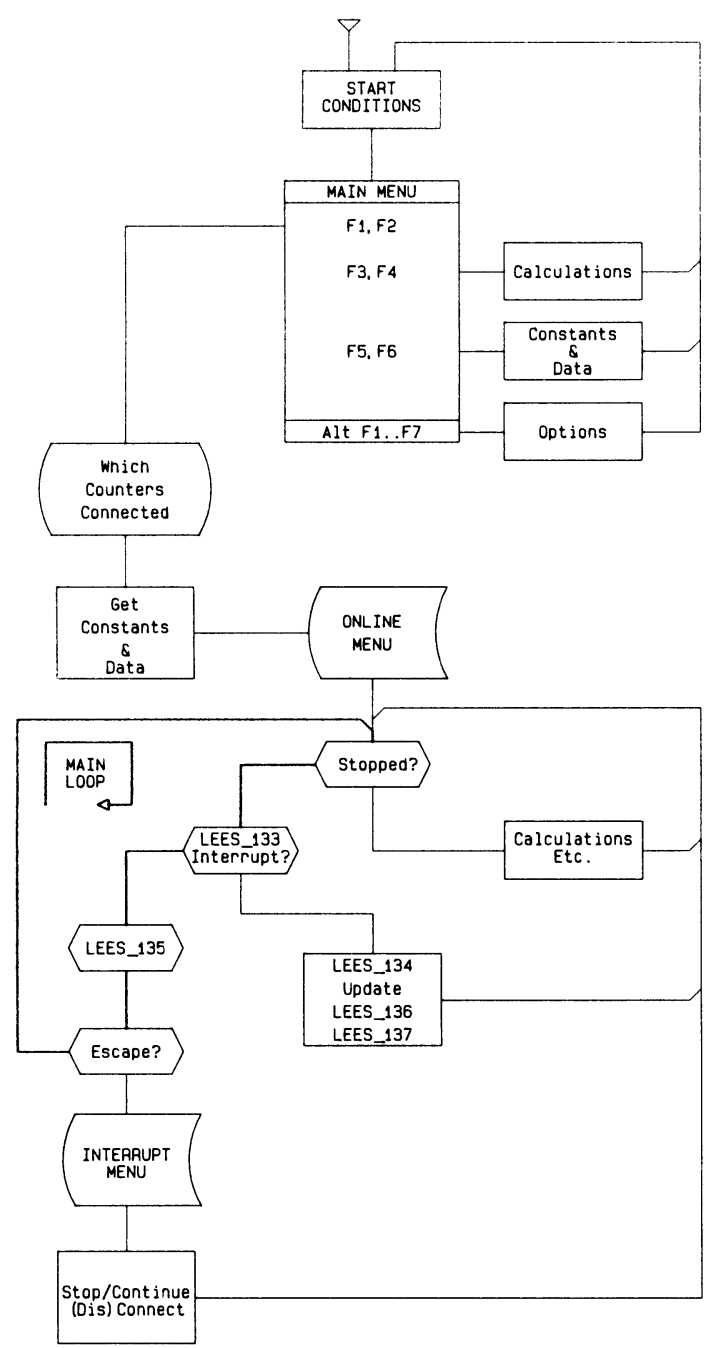

Fig. 4. Simplified flow diagram for the program, TELBUIS

The loop can be interrupted in only two ways: 1) one of the channels of the counter controller unit generates an interrupt, 2) from the program, TELBUIS, by hitting the escape key.

The hardware interrupt is generated when a measuring cycle (as a rule, $100 \mathrm{~min}$ ) is finished. Device 133 (program LEES_133) checks for hardware interrupts and communicates which counter generated the interrupt. Next, the seven channels of the counter controller unit for the measurement cycle just finished will be read out by the computer (program LEES_134), as well as the measurement time (LEES_136) and the barometer-, pressure- and temperature-gauge readings (LEES_137). The program updates the data file on disk, and continues with the main loop.

In case of a software-generated interrupt, the program stops, and an interrupt menu gives the user five choices: continue the main loop (in case "escape" was used by accident), leave the program, restart the program, disconnect a counter from the program, or connect to the program a counter that was not active thus far.

During the main loop, i.e., always operating when the counters are measuring, the program produces on the screen of the computer an online menu (Fig. 5), showing key data for every 
counter, such as which counter is connected (indicated by status), GrN/GT number, Channel 0 (no. of beta counts), Channel 3 (purity counts) and measuring time per cycle (usually $100 \mathrm{~min}$ ). This continuous readout of the (connected) counters is handled by Device 135 (program LEES_135) and has proven to be very useful as an overview for the performance of all 11 counters.

\begin{tabular}{|c|c|c|c|c|c|c|c|}
\hline $\begin{array}{l}\text { counter : } 1 \\
\text { GrN }: \\
\text { chan. }:= \\
\text { chan. }: \text { : } \\
\text { meas.time: }\end{array}$ & $\begin{array}{l}\quad \text { status : } \\
18985 \\
7 \\
198 \\
100\end{array}$ & $=1$ & $\mid \begin{array}{l}\text { counter : }: 5 \\
\text { GT } \quad: \\
\text { chan. } 0: 5 \\
\text { chan. : : } \\
\text { meas.time: }\end{array}$ & $\begin{array}{l}\text { Status: } \\
6697 \\
208 \\
235 \\
100\end{array}$ & & & $\mid \begin{array}{l}\text { counter : } 9-4 \text { status : } 1 \\
\text { GrN : } 18546 \\
\text { Chan. : : } 89 \\
\text { chan. : : } 82 \\
\text { meas.time: } 100\end{array}$ \\
\hline $\begin{array}{l}\operatorname{counter}: 2 \\
\text { GrN }: \\
\text { chan. } 0: \\
\text { chan. } 3: \\
\text { meas.time: }\end{array}$ & $\begin{array}{l}\text { status } \\
18884 \\
208 \\
122 \\
100\end{array}$ & $: 1$ & 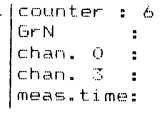 & $\begin{array}{l}\text { status: } \\
99999 \\
172 \\
212 \\
100\end{array}$ & $:$ & 1 & $\begin{array}{l}\text { Counter : } 9-\mathrm{B} \text { status : } 1 \\
\text { GrN }: 18546 \\
\text { chan: }:=240 \\
\text { chan.: : } 199 \\
\text { meas.time: } 100\end{array}$ \\
\hline $\begin{array}{l}\text { counter : } 3 \\
\text { GrN } \\
\text { chan. } 0: \\
\text { chan. } 3: " \\
\text { meas. time: }\end{array}$ & status : & $: 0$ & 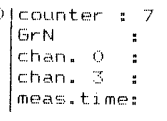 & $\begin{array}{l}\text { status : } \\
18889 \\
148 \\
159 \\
100\end{array}$ & & 1 & $\mid \begin{array}{l}\text { Counter : } 9-\mathrm{C} \text { status : } 1 \\
\text { GrN }: 18546 \\
\text { chan. }:=63 \\
\text { chan. : : } 127 \\
\text { meas.time: } 100\end{array}$ \\
\hline $\begin{array}{l}\text { counter : }{ }^{4} \\
\text { GT } \\
\text { chan. o : } \\
\text { chan.: : } \\
\text { measintime: }\end{array}$ & $\begin{array}{l}\text { Etatus : } \\
1111 \\
43 \\
70 \\
100\end{array}$ & & $\begin{array}{l}\text { counter : } 8 \\
\text { GrN } \\
\text { chan. } 0: " \\
\text { chan. } 3: " \\
\text { meas.time: }\end{array}$ & $\begin{array}{l}\text { Status : } \\
11111 \\
184 \\
51 \\
100\end{array}$ & & 1 & $\begin{array}{l}\text { date }: 1051991 \\
\text { time }: 133028 \\
\text { ESC for stopping }\end{array}$ \\
\hline
\end{tabular}

Fig. 5. Online screen during data acquisition

All data are recorded on disk, the file names keyed with the date the run was started and the counter number. The files are K_ddmmyy.TBx for counter constants, G_ddmmyy.TBx for the measurement data, A_ddmmyy.TBx for the file containing the raw data of the measurement cycles, B_ddmmyy.TBx the report (usually containing one full day of data) based on pre-analysis of the raw data, and D_ddmmyy.TBx the definitive results. In this notation, "ddmmyy" is the usual notation for day/month/year, and " $x$ " corresponds to the counter number. The definitive results are usually calculated on an offline PC, using the same program, TELBUIS. Several runs (i.e., several files B_ddmmyy) can be averaged together. The final ages are calculated at this stage.

This setup of file bookkeeping allows automatic processing/reporting. Especially in a future network environment, the files with definitive results can be connected to other programs, such as the new Groningen radiocarbon database (van der Plicht 1992), calibration programs (van der Plicht \& Mook 1989), administrative software or even programs from outside users.

\section{REFERENCES}

Borland 1989 Turbo Pascal. Scotts Valley, California. Brenninkmeijer, C. A. M. and Mook, W. G. 1979 The effect of electronegative impurities on $\mathrm{CO}_{2}$ proportional counting: An on-line purity test counter. In Berger, R. and Suess, H. E., eds., Radiocarbon Dating. Proceedings of the 9 th International ${ }^{14} \mathrm{C}$ Conference. Berkeley, University of California Press: 185-196.

Groeneveld, D. J. 1977 (ms.) Tritium analysis of environmental water. Ph.D. dissertation, University of Groningen.

Grootes, P. M. 1977 (ms.) Thermal diffusion, isotopic enrichment and radiocarbon dating beyond 50,000 years BP. Ph.D. dissertation, University of Groningen.

Hut, G., Keyser, J. and Wijma, S. 1983 A multiple proportional ${ }^{14} \mathrm{C}$ counter system for milligram-sized samples. In Stuiver M. and Kra, R. S., eds., Proceed- ings of the 11 th International ${ }^{14} \mathrm{C}$ Conference. Radiocarbon 25: 547-552.

Mook, W. G. and Streurman, H. J. 1983 Physical and chemical aspects of radiocarbon dating. In Mook, W. G.' and Waterbolk, H. T., eds., Proceedings of the International Groningen Symposium ${ }^{14} \mathrm{C}$ and Archaeology. PACT 8: 31-55.

Tans, P. P. and Mook, W. G. 1978 Design, construction and calibration of a high accuracy carbon- 14 counting set up. Radiocarbon 21: 22-40

van der Plicht, J. 1992 The new Groningen ${ }^{14} \mathrm{C}$ data base. Radiocarbon, this issue.

van der Plicht, J. and Mook, W. G. 1989 Calibration of Radiocarbon ages by computer. In Long, A. and Kra, R. S., eds., Proceedings of the 13 th International ${ }^{14} \mathrm{C}$ Conference. Radiocarbon 31(3): 805-816. 